\title{
PROPERTIES OF VISCOSE VORTEX YARNS DEPENDING ON TECHNOLOGICAL PARAMETERS OF SPINNING
}

\author{
Eva Moučková1, Iva Mertová1, Petra Jirásková1, Gabriela Krupincová1, Dana Křemenáková ${ }^{2}$ \\ ${ }^{1}$ Technical University of Liberec, Faculty of Textile Engineering, Department of Textile Technologies \\ ${ }^{2}$ Department of Material Engineering, Studentská 2, 46117 Liberec 1, The Czech Republic, \\ Telephone: +420 48535 3274; Fax: +420 48535 3542, eva.mouckova@tul.cz
}

\begin{abstract}
:
This paper analyzes the relationship between technological parameters of spinning of $100 \%$ CV Vortex yarns of different counts and its selected geometrical parameters (a lead of helix of wrapping fibre ribbon, yarn diameter) as well as yarn properties. The number of twist of wrapping fibre layer is determined. The effect of the yarn delivery speed, hollow spindle diameter, and the main draft on the hairiness, mass irregularity, tenacity, elongation, resistance to abrasion and bending rigidity of Vortex yarn is observed. The yarn properties are compared with the properties of open-end rotor spun yarns. Slivers of the same spinning lot were used for the production of both kinds of yarn. The results showed that the delivery speed in combination with spindle diameter affects yarn diameter, hairiness and abrasion resistance. Mass irregularity and imperfections of yarn is mainly affected by the main draft of drafting unit. Technological parameters of spinning do not affect the level of bending rigidity of the Vortex yarn. Tested rotor spun yarns had a larger diameter, higher hairiness, lower tenacity and higher elongation, lower mass irregularity and number of imperfections, higher abrasion resistance and lower bending rigidity compared to tested Vortex spun yarns.
\end{abstract}

\section{Keywords:}

Vortex spun yarn, rotor spun yarn, viscose fibres, yarn properties

\section{Introduction}

Vortex spun yarn received its name from the spinning system developed by Murata Machinery Ltd. - Murata Vortex spinner (MVS). The spinning system is one of the unconventional systems for yarn manufacturing, classified into the group of jet spinning. A different principle of yarn forming compared with open-end rotor (next OE-rotor) or ring spinning results in a different yarn structure. Owing to twist, all or some of the fibres take up the required helical disposition in the ring spun yarn. Twisting takes place from the outside inwards. Twisting during rotor spinning takes place from the outwards inside too; in the core, fibres are disposed in a helical form but less parallel; in the sheath, fibres are arranged more random, they are less twisted. Some of the fibres are wrapped around already spun yarn [1]. Vortex spun yarn consists of two layers - a core bundle without twist, in which fibres are arranged parallel to the yarn axis and the wrapping layer, which is twisted around the core. Fibres in wrapping layer are so formed that the top end of fibres converges to the centre of the yarn and the trailing end together with other fibres wind the core due to swirling air [2]. Basal has described the trajectory of the fibres using traced fibres and determined a percentage of fibres type in the Vortex yarn [3]. Due to different way of fibres arrangement in the yarn, the properties of yarn also change. Compared to the ring spun yarn, the Vortex yarn has less hairiness, better appearance, higher moisture absorption. Woven fabrics made from the Vortex yarn show better resistance to pilling, abrasion and wash [2]. Properties of Vortex yarn were evaluated in many works, for example, in the work [4] and [3], where authors have compared Vortex yarn (MVS) and air-jet yarn Vortex-J (MJS) using various blend ratio of polyester (next PES) and cotton (next CO) fibres. Soe et al. have compared structure and selected properties of $100 \%$ CO ring, rotor and Vortex spun yarn of count of 20 tex [5]. They have investigated statistical insignificant difference between mass irregularity $\left(\mathrm{U}, \mathrm{CV}_{\mathrm{m}}\right.$ values) of tested kinds of yarn. Vortex spun yarns showed higher number of thick places and neps compared to other two kinds of yarn. Hairiness of Vortex yarn in the length category $1 \mathrm{~mm}$, measured using the Zweigle instrument, had the same level as rotor yarns but lower than ring spun yarns. Hairiness of Vortex yarn in the length category $3 \mathrm{~mm}$ was significantly lower than one of two other yarn kinds. Ring spun yarns had the highest strength from all tested yarns. Bending rigidity of Vortex yarn was the highest. Authors have also recorded higher breaking elongation, lower variation coefficient of tenacity and elongation compared to ring and rotor spun yarns. Basal and Oxenham have studied the effect of parameters influencing the yarn formation process on the MVS machine (nozzle angle, air pressure, spindle diameter, delivery speed and distance between front roller and spindle) on the structure and properties of $100 \%$ CO Vortex spun yarns of count $\mathrm{Ne} 28$ [6]. They found out that air pressure and spindle diameter affects only yarn hairiness (higher air pressure and smaller spindle diameter leads to low hairiness); low delivery speed causes less number of thick places and less hairiness; combination of delivery speed and nozzle angle influences yarn hairiness significantly. Kuthalam and Senthilkumar have analysed properties of Vortex yarn of count of 20 tex spun from $100 \%$ PES fibres of different fineness at various delivery speeds [7]. According to them, delivery speed does not affect any yarn properties except hairiness. Price et al. also conducted studies on a similar topic [8]; they have observed the effect of $\mathrm{CO}$ fibres 
on the Vortex yarn properties. Ortlek et al. have investigated the influence of different spindle diameter and spindle working period on properties of $100 \%$ viscose Vortex yarn [9]. They found out that as the spindle diameter is increased, hairiness of yarn decreases and yarn irregularity and tenacity reduces. Also, Erdumlu et al. presented a comparison of the properties of Vortex, rotor and ring spun yarns made from $100 \% \mathrm{CO}$, $100 \% \mathrm{CV}$ and $50 / 50 \mathrm{CO}$-modal fibres in relation to fabric knitted from these yarns [10]. The results confirmed the lower hairiness of Vortex yarn and the fact, that knitted fabrics made from Vortex yarn have lower pilling resistance. Viscose Vortex yarns showed the best tenacity and hairiness compared with yarns spun from other kind of tested fibres. Erdumlu et al. and Tyagi et al. have analysed structure of $100 \%$ CO Vortex spun yarn [11], [19]. They showed that the amount of wrapping fibres in the yarn rises with increasing yarn fineness (decreasing values in tex unit). They also confirmed that the finer the yarn is, the worse the yarn irregularity is, with a significant increase in the number of yarn faults

This work follows the previous knowledge concerning the properties of Vortex spun yarn and its relation to the technological parameters of yarn spinning. The current state of knowledge is extended to selected geometrical parameters and properties of $100 \%$ CV carded Vortex spun yarns.

\section{Experiment}

The paper analyzes the relationship between technological parameters of spinning (yarn delivery speed in combination with the spindle diameter and main draft) of $100 \%$ viscose carded Vortex yarn of various counts and selected geometrical parameters of yarns (a lead of helix of wrapping fibre layer, yarn diameter) as well as yarn properties. Yarn hairiness, mass irregularity, tenacity, breaking elongation, yarn abrasion resistance and bending rigidity are evaluated. Properties of Vortex yarns are compared with that of rotor spun yarn of the same counts spun from slivers of the same spinning lot.

Table 1. Main technological parameters

Table 1. Main technological parameters
\begin{tabular}{|c|c|c|c|c|}
\hline Yarn & Yarn count [tex] & $\begin{array}{c}\text { Delivery speed } \\
{[\mathrm{m} / \mathrm{min}]}\end{array}$ & $\begin{array}{c}\text { Spindle diameter } \\
\text { [mm] }\end{array}$ & Main draft \\
\hline Vortex & 16.5 & 325 & 1.1 & 55 \\
\hline Vortex & 20 & 325 & 1.1 & 55 \\
\hline Vortex & 25 & 325 & 1.2 & 45 \\
\hline Vortex & 16.5 & 350 & 1.2 & 45 \\
\hline Vortex & 20 & 350 & 1.2 & 45 \\
\hline Vortex & 25 & 350 & 1.3 & 35 \\
\hline Vortex & 16.5 & 375 & 1.3 & 35 \\
\hline Vortex & 20 & 375 & - & 35 \\
\hline Vortex & 25 & 375 & - & - \\
\hline OE-rotor & 16.5 & - & & 45 \\
\hline OE-rotor & 20 & - & & \\
\hline
\end{tabular}

Viscose fibres of average length of $38 \mathrm{~mm}$ and average fineness of $1.43 \mathrm{dtex}$ were used for the yarn production. A series of 9 kinds of yarn (count of 16.5 tex, 20 tex, 25 tex) were spun from the carded and consequently twice drawn sliver of fineness 3.5 ktex using Murata Vortex Spinner MVS 861. Yarns were produced at various levels of main draft (4-line drafting unit), diameter of the slots of the hollow spindle (spindle diameter) (see Figure 1) and yarn delivery speed. Main technological parameters of MVS 861 machine are shown in Table 1. Air pressure in the nozzle was set on value $0.5 \mathrm{MPa}$ for all kinds of yarn, distance $L$ between a delivery roller and spindle was $19.5 \mathrm{~mm}$. Different yarn counts were achieved by changing the break draft. For comparison, rotor yarns of count 16.5 tex and 20 tex were spun on the OE-rotor spinning machine BT from slivers produced the same way from the same spinning lot. The Phrix twist coefficient $60 \mathrm{ktex}^{2 / 3} \cdot \mathrm{m}^{-1}$ was used for rotor yarn twisting.

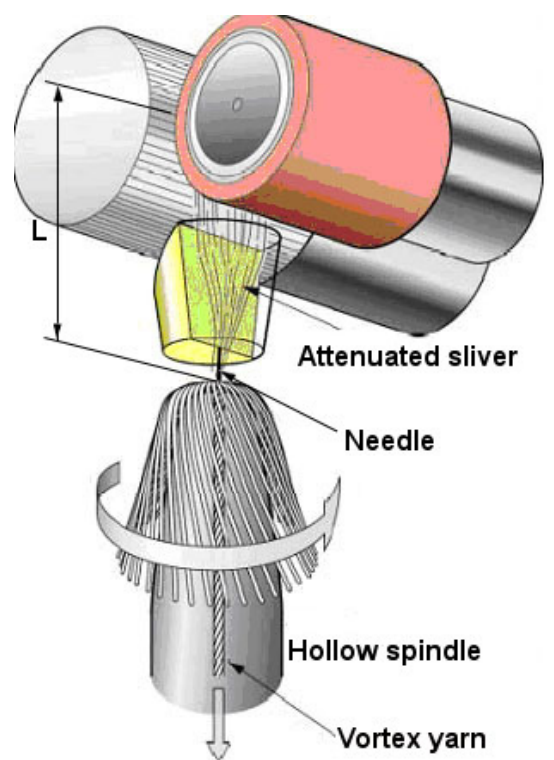

Figure 1. Scheme of spinning unit of Vortex spinning machine [12] 


\subsection{Methods}

\section{Structure of OE-rotor and Vortex spun yarns}

During yarn manufacture on the OE-rotor spinning machine, the fibres are twisted-in at the rotating free end of yarn from the yarn surface towards the centre. Some fibres wrap the yarn in one place - so called belt fibres. Longitudinal views of rotor yarn, captured using an electron microscope, are shown in Figure 2.

At the spinning of Vortex yarns, all fibres are formed from the yarn centre towards the wrapping layer. As seen from longitudinal views shown by the electron microscope (Figure 3), a portion of fibres forms a regular supporting part of the yarn (a core), whereas a portion constitutes a wrap. The core is composed of roughly parallel fibres and the ribbon wraps it at regular intervals. According to [13], the portion of wrapping fibres is $20-30 \%$.

The number of twist of Vortex yarn cannot be either measured using a twist tester or defined by a conventional method (by determination of machine twist as a ratio of number of revolution of twisting device and yarn delivery speed). Thus, the number of twist of wrapping ribbon of Vortex yarn was determined experimentally based on the model representation of ribbon fibres [14]. We assume that the wrapping fibres form the flat ribbon in a helical trajectory; the ribbon wraps around the core regularly. We can define the number of turns per unit length as a ribbon twist, see Figure 4.

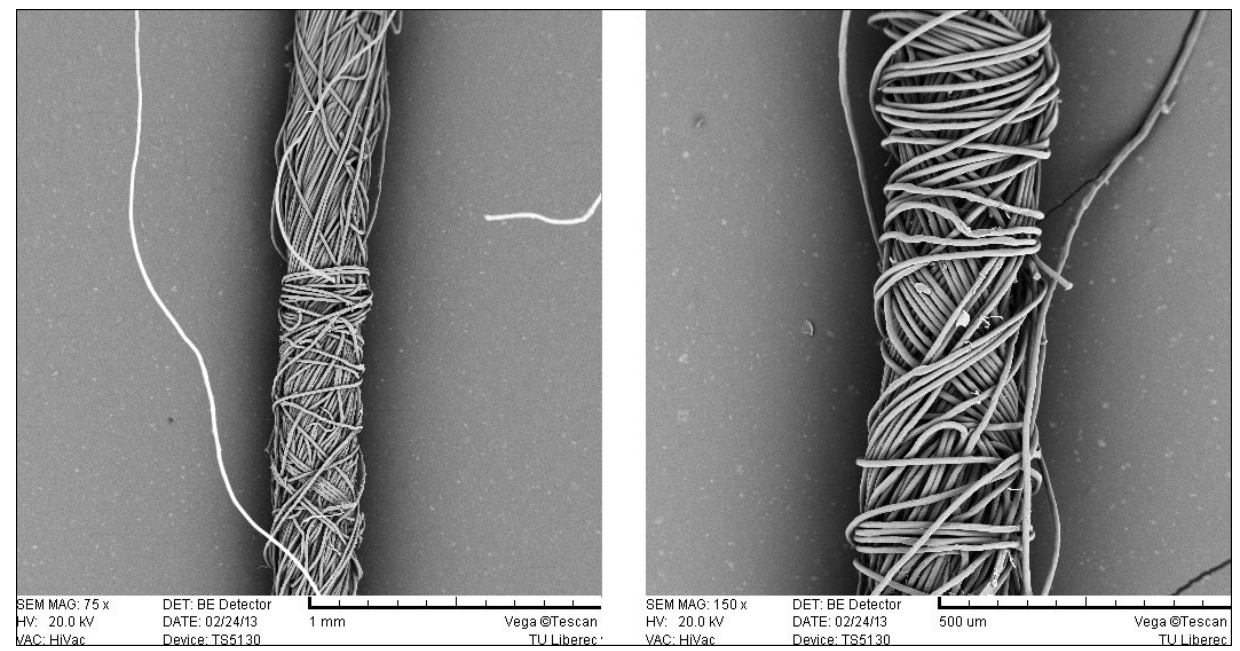

Figure 2. Surface structure of OE-rotor spun yarn (yarn count: 20 tex; magnification: 75x and 150x)

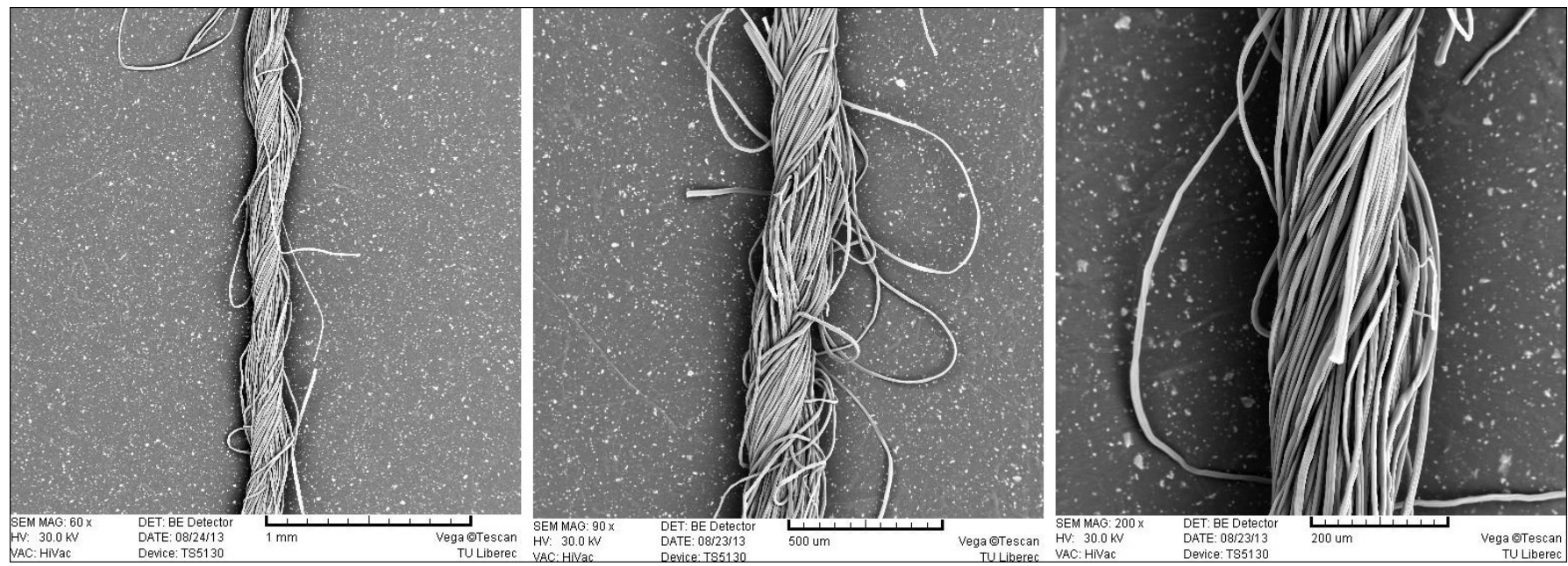

Figure 3. Surface structure of Vortex yarn (yarn count: 16.5 tex; magnification: 60x, 90x, 200x)

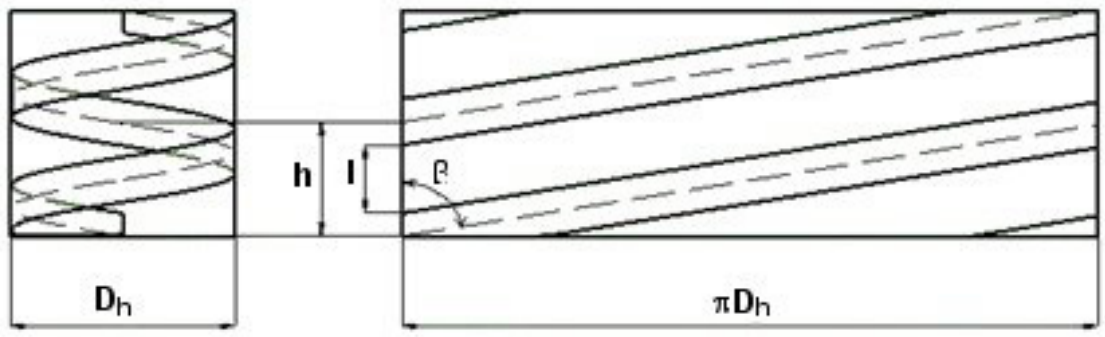

Figure 4. Model representation of fibre ribbon [14] 
The axis of ribbon forms a helix on the cylinder of diameter $D_{h}$, which corresponds to the yarn diameter. The lead of helix of wrapping ribbon is labelled $h$ (magnitude $l$ is a distance between ribbon edges). For the number of twist $Z$ of fibre ribbon, the formula (1) holds:

$$
Z=1 / h
$$

The measurement of lead of helix $h$ of wrapping fibre ribbon was done by means of image analysis NIS Elements, see Figure 5. Fifty measurements were done from each type of yarns.

The number of twist of wrapping fibre ribbon was calculated according to formula (1) and recalculated per $1 \mathrm{~m}$ of yarn.

\section{Yarn diameter}

The yarn diameter, as one of the important parameters of yarn needed, for example, for prediction of woven fabric properties, especially its thickness [15], was measured using the optical sensor of Uster Tester IV-SX. Five measurements were done at speed $400 \mathrm{~m} / \mathrm{min}$ for $5 \mathrm{~min}$ from each type of yarns.

\section{Yarn hairiness, mass irregularity, imperfects}

The yarn hairiness was measured simultaneously with the yarn diameter, yarn mass irregularity and yarn faults using the apparatus Uster Tester IV-SX. Measurement was carried out under the same condition as the measurement of yarn diameter. Yarn hairiness was measured on the Zweigle G567 instrument too. The yarn length of $100 \mathrm{~m}$ of yarn was measured at speed $50 \mathrm{~m} / \mathrm{min}$ per each bobbin. Parameters of hairiness $S 12$ (total number of fibre ends protruding from the yarn body of length $2 \mathrm{~mm}$ ) and $S 3$ (total number of protruding fibre ends longer than $3 \mathrm{~mm}$ ) were observed.

\section{Yarn tenacity and elongation}

The yarn tenacity and elongation was measured using the Instron 4411 device as per the standard condition defined by ČSN-EN-ISO-2062 [16].

\section{Yarn abrasion resistance}

The measurement of yarn abrasion resistance was done on the device Zweigle Abrasion Tester. The measuring principle is based on stress of parallel tensioned threads by constant friction force applied by a cylindrical body covered with an abrasive surface. The body rotates at a constant speed. The average number of body revolutions till yarn breakage is used as a criterion of abrasion resistance. The measurement was carried out at the yarn preload of $20 \mathrm{cN}$. The abrasive paper of type TP $800 \mathrm{C}$ was used. Sixty measurements were done for each type of yarn.

\section{Yarn bending rigidity}

The bending properties of textiles (yarn, fabric) can be expressed by the bending rigidity $E l$, which can be defined as the resistance of textile against flexion by its specific weight and external force. It affects yarn workability during weaving or knitting and a number of other important properties of textiles such as drape, deformability, handle, etc. The formula (2), derived in the work [17], was used for determination of yarn bending rigidity in this work. The equation considers the yarn as a fixed-end beam, on which its specific weight acts. The bending rigidity of yarn is therefore given by the formula:

$$
E I=\frac{q I x_{0}^{2} x_{c}^{2}}{\left(2 x_{c}+x_{0}\right) w_{0}}
$$

where $E l$ is bending rigidity $\left[\mathrm{Nm}^{2}\right], q$ is specific weight of textile $\left[\mathrm{Nm}^{-1}\right], l$ is sample length after restraint $[\mathrm{m}], x_{0}$ and $w_{0}$ are coordinates of end point $(\mathrm{A})$ of deflection curve and $x_{c}$ is $\mathrm{x}$-coordinate of centre of gravity of deflection curve, see Figure 6.

The experiment was performed in accordance with the internal standard [18]. During the experiment, yarn was clamped in a special jig so that one end of yarn was fixed between the jaws and the other end was free. The deflection curve of yarn was captured by a digital camera. From the obtained image, parameters, required for calculation of yarn bending rigidity according to the equation (2), were determined by NIS Elements image analysis. Thirty measurements were carried out at a clamping length of $500 \mathrm{~mm}$ for each type of yarn.

Data were treated by usual statistical procedures. Normality and homogeneity of measured values were tested, average value and its $95 \%$ confidence interval was calculated. The effect of the yarn count and technological parameters of spinning were analysed using the two-factor analysis of variance (ANOVA) at the significance level of $5 \%$.

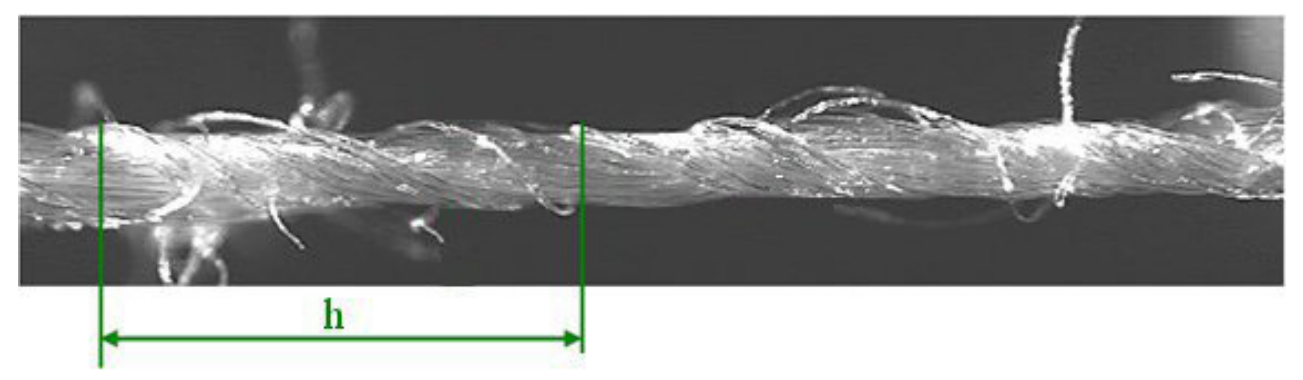

Figure 5. Longitudinal view on Vortex yarn 


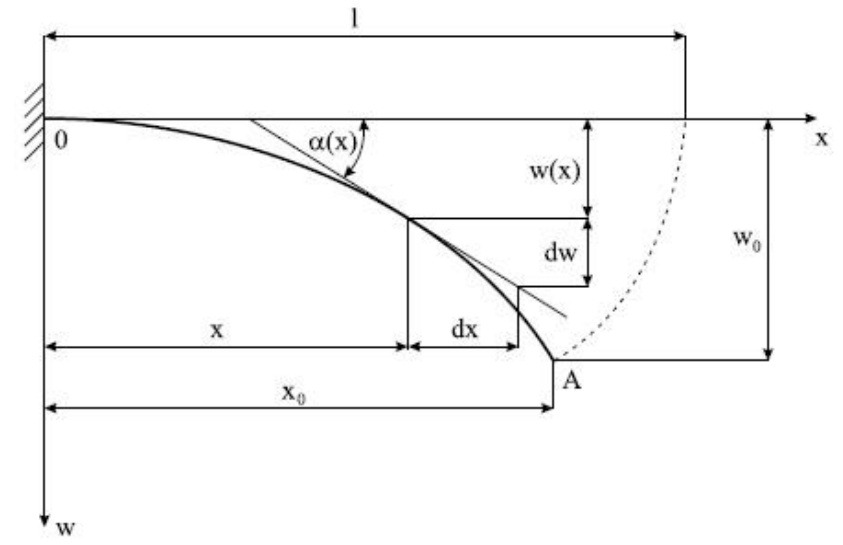

Figure 6. Illustration of deflection curve of yarn

\section{Results and discussion}

\section{Structure of OE-rotor and Vortex spun yarns}

The lead of helix of wrapping fibre ribbon $(h)$ is shown in the Figure 8 , the number of twist of wrapping fibre ribbon $(Z)$ in dependence of yarn count is mentioned in the Figure 9. A set of numbers, listed in the explanatory meaning of each colour (e.g. 325, 1.1, 55) used in the graphs in Figure 8 - Figure 21, means: yarn delivery speed, spindle diameter, main draft.

Especially in the case of Vortex yarns spun at delivery speed of 325 and $375 \mathrm{~m} / \mathrm{min}$, it can be seen that the coarser yarns have a lower number of twists per unit length, that is, a greater lead of helix of wrapping fibre ribbon was recorded. This trend is also apparent in the ring or rotor spun yarns. The number of twists per unit length imparted into the yarns, spun from the same raw material, generally depends not only on the fineness (diameter) of twisted fibrous assembly, but, in technological terms, also on the ratio of revolution of twisting device and delivery speed of yarn. But, the number of twist of Vortex yarn is not a directly adjustable parameter on the MVS machine. In the case of Vortex yarn, thickness (fineness) of supporting layer of yarn (the core), air pressure in the nozzle and delivery

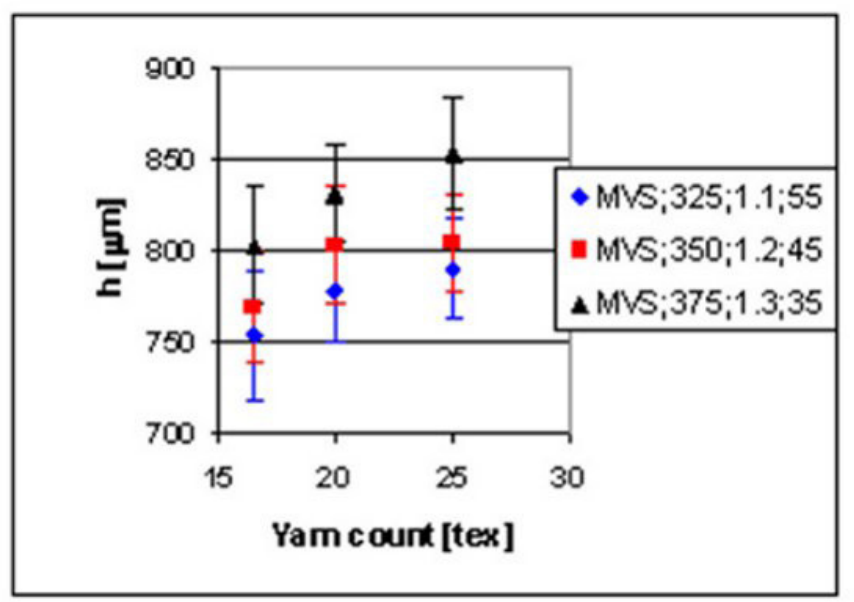

Figure 8. Lead of helix (h) of wrapping fibre ribbon

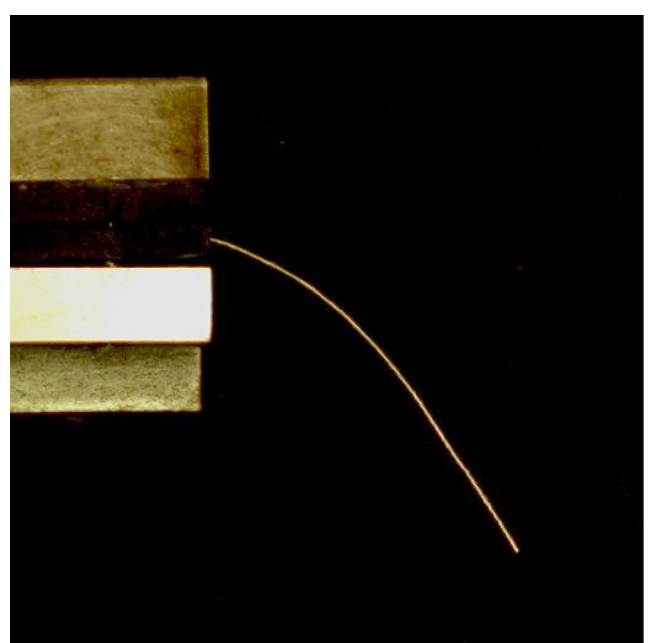

Figure 7. The digitised image of measured yarn sample

speed affect the lead of helix of wrapping fibre ribbon. We can assume that at the same air pressure in the nozzle (i.e. the same intensity of twisting-in of wrapping fibres to the core) the lead of helix would be affected by fineness (diameter) of yarn core and delivery speed. It is evident from Figure 9 that with increasing delivery speed and spindle diameter the number of twist inserted into wrapping fibres ribbon decreases (i.e. lead of helix of wrapping ribbon increases). At higher speed, fibres of wrapping layer might be spread over a greater length of yarn within one turn per unit length. Thus, at constant air pressure, the number of turns per unit length of yarn is less, that is. the number of twists of wrapping fibres is lower. According to the two-factor ANOVA, the influence of technological parameters and count of tested yarn on the lead of helix of wrapping fibre ribbon is significant at the level of significance 0.05 .

The number of twist of tested OE-rotor spun yarns is lower than twist of wrapping fibres ribbon of Vortex yarns.

\section{Yarn diameter}

The average values and corresponding 95\% confidence intervals of yarn diameter are shown in Figure 10. Coarser yarns (with higher value of count in tex) have higher diameter,

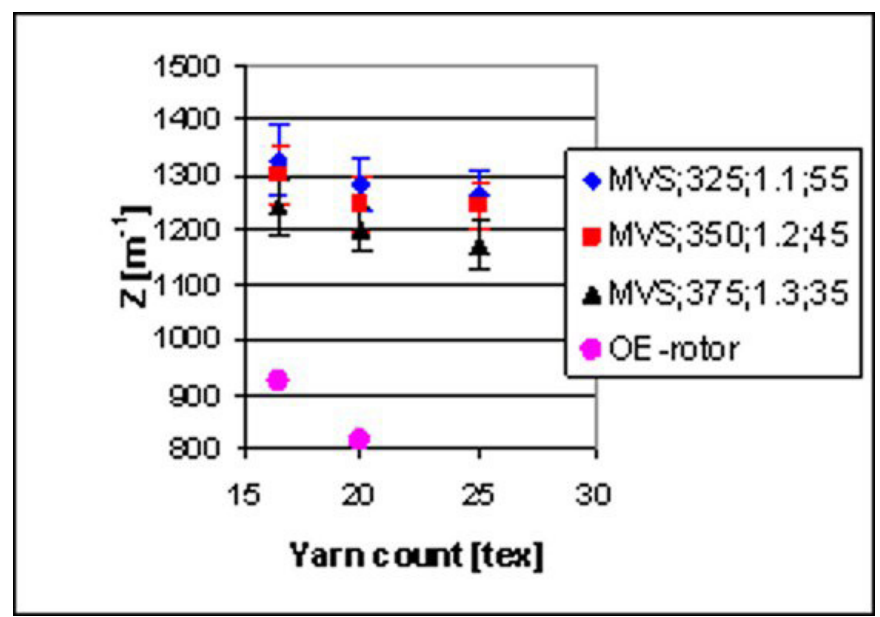

Figure 9. Number of twists $(Z)$ of wrapping fibre ribbon 
which is also usual for yarns spun by other methods. In the case of fibres with the same fineness, the coarser yarn contains a higher number of fibres and therefore, it has a larger diameter. It is evident that the diameter of Vortex yarn decreases with increasing delivery speed and spindle diameter. The key part of this fact is probably the spindle diameter, where a more intense compression of fibres in the yarn core occurs. The results of two-factor variance analysis (ANOVA) confirmed a statistically significant influence of yarn count and technological parameters of MVS machine on the yarn diameter at a significance level of $5 \%$. For the comparison, diameters of tested OE-rotor spun yarns are shown in Figure 10. The diameters of Vortex yarns are significantly less than the rotor yarns. It is due to the technology of yarn production on the spinning machine, particularly a way of yarn twisting.

\section{Yarn hairiness}

The average value of yarn hairiness, measured by the Uster Tester IV-SX, and corresponding 95\% confidence interval for each type of yarn is shown in Figure 11.

Towards to coarser yarn, a slight increase and than decrease of yarn hairiness are visible. Differences among yarn hairiness values in the term of yarn count are not high. However, the systematic influence of technological parameters of Vortex yarn

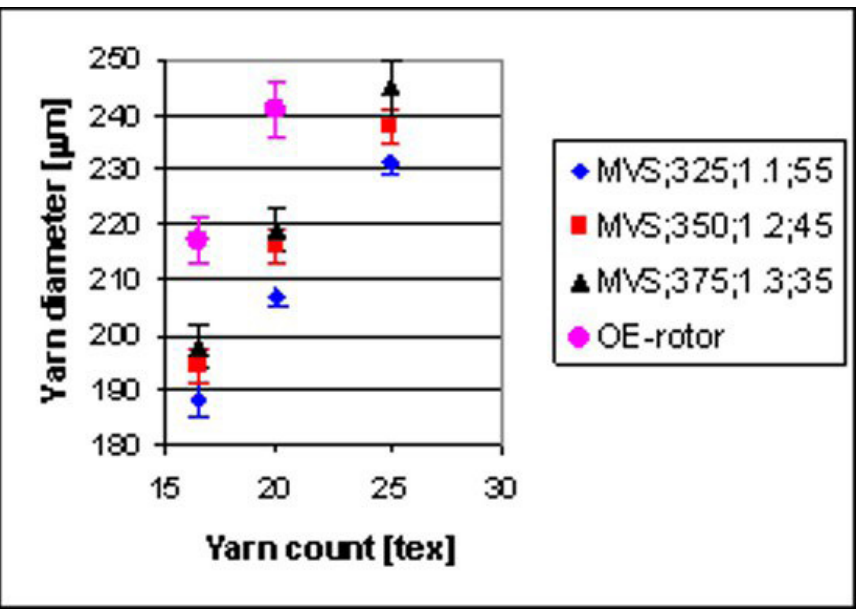

Figure 10. Yarn diameter

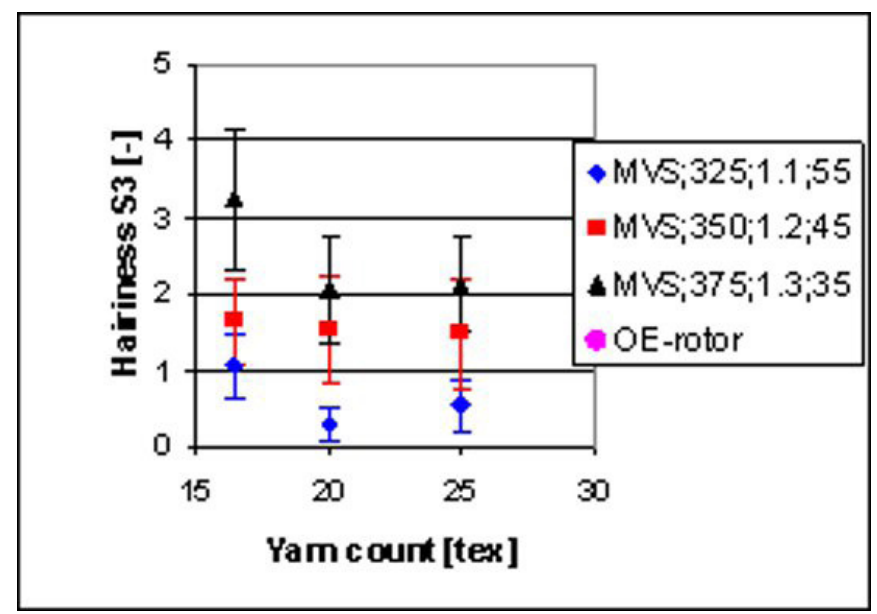

Figure 12. Yarn hairiness $S 3$ spinning is obvious. The yarn spun using the smallest spindle diameter and lowest delivery speed has the lowest hairiness values and conversely. It should be explained by the fact that wrapping fibres are more twisted-in into the yarn core at the lowest tested delivery speed compared to higher speed (there is more time for fibres for twisting-in into yarn). Also fibres in the yarn core are more compressed due to the lowest spindle diameter. The results of two-factor ANOVA confirmed significant influence of yarn count and technological parameters of yarn spinning at significance level of $5 \%$. Hairiness of OE-rotor spun yarns has higher variability compared to Vortex spun yarns. Average value of rotor yarns hairiness are higher compared to Vortex yarn, but they approach the hairiness value of Vortex yarn spun using the largest spindle diameter and the highest delivery speed.

Average values of yarn hairiness in the length categories S3 and S12 measured by the Zweigle hairiness tester and corresponding $95 \%$ confidence intervals of hairiness are shown in the Figure 12 and 13.

From the results, it is evident that the highest value of hairiness in the cumulative length category $S 3$ was recorded at fineness of 16.5 tex. The yarn hairiness decreases with increasing value of yarn count. The results also show great variability of hairiness values $S 3$, which is reflected in the wide confidence intervals

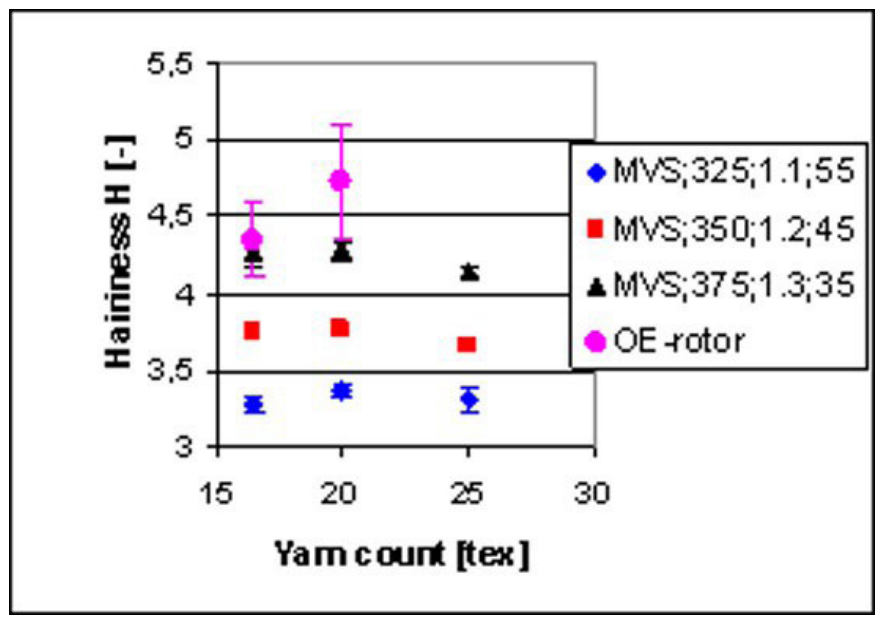

Figure 11. Yarn hairiness measured by Uster Tester

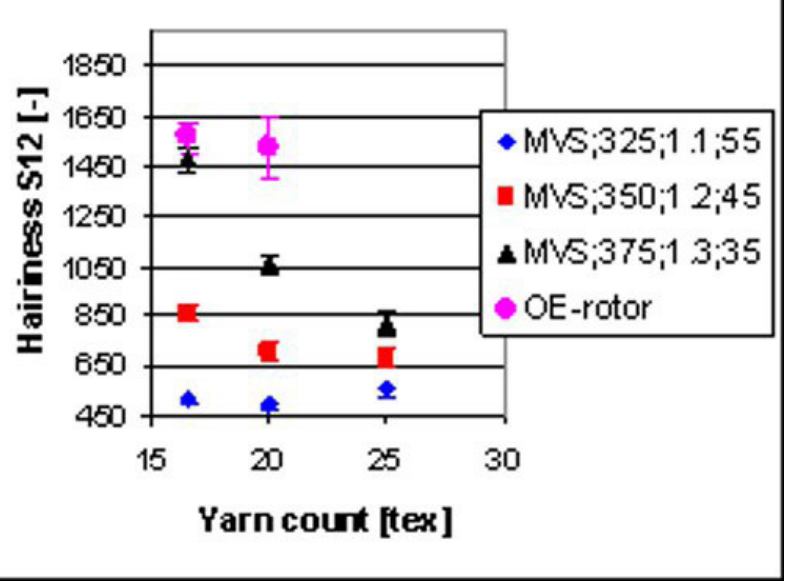

Figure 13. Yarn hairiness S12 
in Figure 12. The influence of technological parameters on hairiness in the category $S 3$ is evident. The yarns spun with the smallest spindle diameter and the lowest delivery speed has the lowest hairiness and conversely. The two-level ANOVA shows a statistically significant influence of delivery speed on the hairiness S3, but insignificant effect of yarn count. The values of rotor yarn hairiness in the cumulative length category S3 are about two orders of magnitude higher than those of tested Vortex yarns. They achieve the level of S3: $266 \pm 13.5$ (yarn count 16.5 tex) and $217 \pm 18$ (yarn count 20 tex). Therefore, hairiness values $S 3$ of rotor spun yarns are not displayed in Figure 12.

The results of Vortex yarn hairiness in the category $S 12$ show the same trend as in the category S3. The highest value was recorded in the yarn of count 16.5 tex spun at highest delivery speed. It nearly achieved the hairiness of rotor yarns. The results of two-level ANOVA show the statistically significant influence of yarn count as well as technological parameters on yarn hairiness in this length category.

\section{Yarn irregularity and imperfects}

The results of yarn mass irregularity $C V_{m}$ is shown in Figure 14 , number of neps $+280 \%$ in Figure 15 , thin places $-50 \%$ are mentioned in Figure 16 and thick places are in Figure 17.

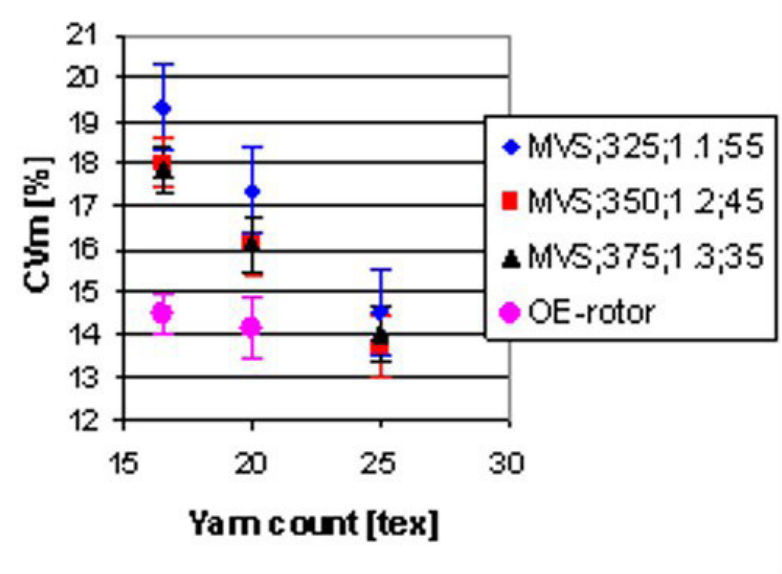

Figure 14. Yarn mass irregularity $\mathrm{CV}_{\mathrm{m}}$

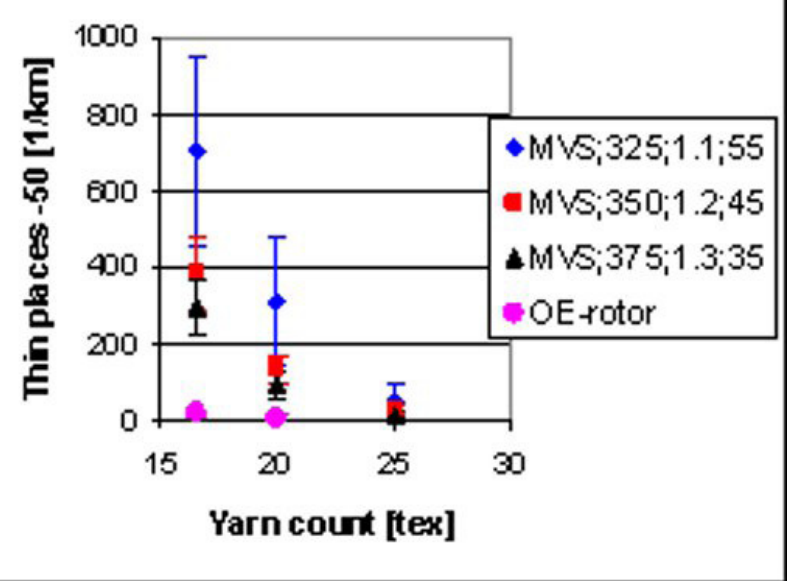

Figure 16. Thin places $-50 \%$
Mass irregularity $\mathrm{CV}_{\mathrm{m}}$, number of thick places $+50 \%$, thin places $-50 \%$ and neps $+280 \%$ of tested Vortex yarns decrease with increasing yarn count (in tex). This is the generally known trend hold for yarns spun by various techniques. In the term of spinning parameters, the yarn spun with the smallest spindle diameter and the lowest delivery speed has the highest value of $\mathrm{CV}_{\mathrm{m}}$ as well as the number of thin and thick places. During spinning of these yarns, the highest value of main draft was adjusted on the MVS machine compared to other tested yarns. The fact that higher value of draft affects both yarn mass irregularity and imperfects negatively is also well known. In our case, this effect is more marked in the case of finer Vortex yarns (16.5 and 20 tex). The value of draft 45 and 35 does not have any significant effect on yarn irregularity and the number of thin and thick places. The results of two-factors ANOVA confirmed the significant influence of both fineness and technological parameters on Vortex yarn irregularity, number of thin $(-50 \%)$ and thick $(+50 \%)$ places at significance level of $5 \%$. The significant effect of yarn count on the number of neps $(+280 \%)$ was also confirmed in contrast to the effect of technological parameters.

The results of evenness testing also show the statistically significant less values of $\mathrm{CV}_{\mathrm{m}}$ of rotor yarns compared to Vortex yarn. It is probably caused by cyclic doubling of fibres in the rotor groove of OE-rotor spinning machine, which has

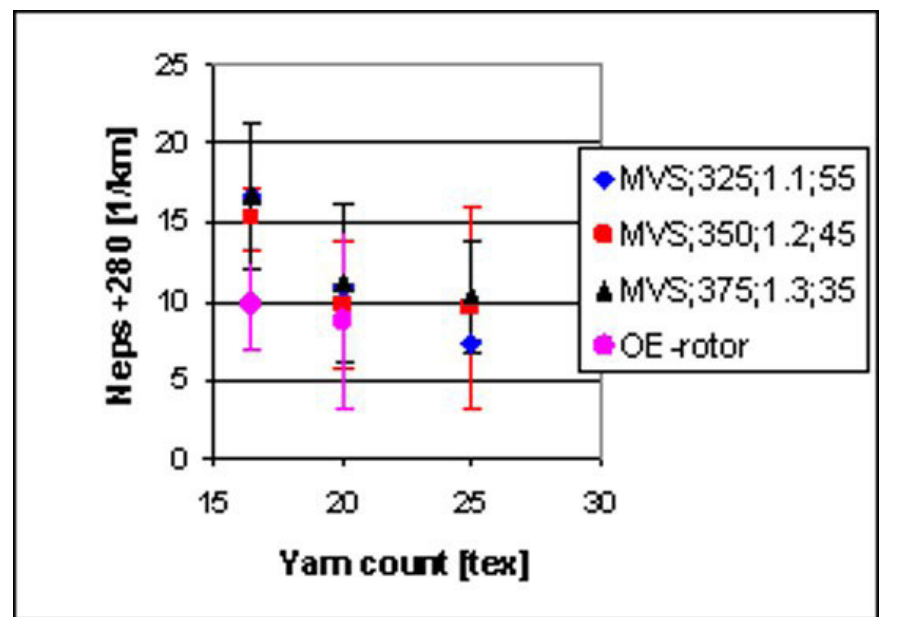

Figure 15. Neps $+280 \%$

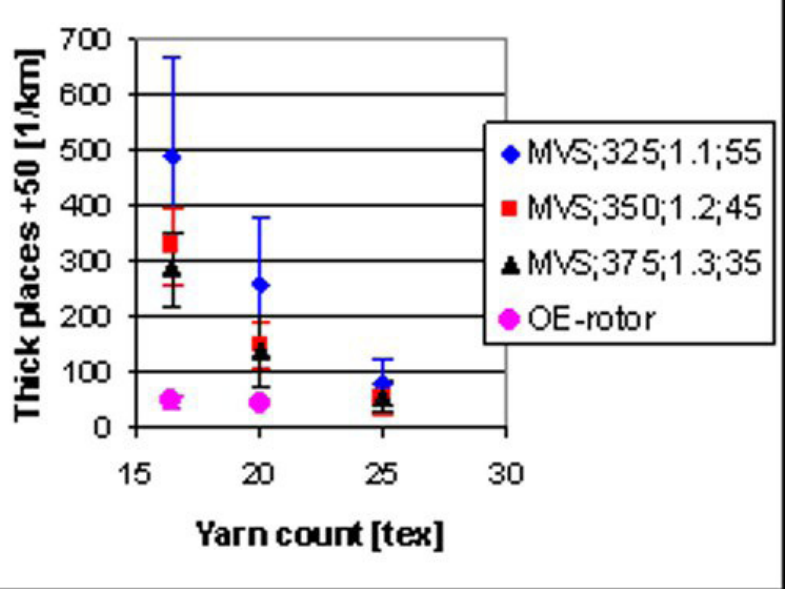

Figure 17. Thick places $+50 \%$ 
a positive effect on yarn mass irregularity. However, during yarn spinning on the MVS machine, doubling is not realised. Also, tested rotor yarns have significantly lower number of thin $(-50 \%)$ and thick $(+50 \%)$ places compared to Vortex yarn. The difference between the number of neps $(+280 \%)$ of rotor and Vortex yarn is statistically insignificant.

\section{Yarn tenacity and elongation}

The average values and corresponding 95\% confidence intervals of yarn tenacity are shown in Figure 18. Results of yarn elongation are mentioned in Figure 19.

The values of tested Vortex yarn tenacity and elongation increase towards coarse yarns. This trend was also recorded in the study [19] where authors tested CO/PES combed Vortex spun yarns and investigated mechanical properties of yarn together with portion of wrapping fibres and core fibres in the yarn. They have found that finer yarns have higher part of wrapping fibres compared to coarse yarns. Their results have been confirmed in the work [11]. Besides fibre strength, the yarn tenacity comes from an arrangement of fibres in the yarn and degree of yarn strengthening. If fibres strength is increased, the yarn reaches a higher strength [20]. Since, according to [19], finer Vortex yarns contain smaller proportion of fibres in the core bundle, they are capable of transferring a lesser load and thus show a lower tenacity compared to coarse yarns consisting of higher portion of core fibres. According to Tyagi et al. [19], the lower breaking elongation values obtained for finer yarn counts might be the result of slightly lower yarn tenacity in finer yarns. In addition, the smaller diameter of the yarn core in finer yarns is wrapped more tightly. This probably makes fibre slippage more difficult.

Although the results of two-factor ANOVA confirmed the statistically significant effect of yarn count and technological parameters on tenacity and elongation of Vortex yarns, the systematic influence of technological parameters of spinning on tenacity and elongation is not apparent from the results. The Vortex yarns of all tested count spun at the lowest delivery speed and with the smallest spindle diameter have the lowest tenacity values. The yarns of fineness 20 and 25 tex spun with

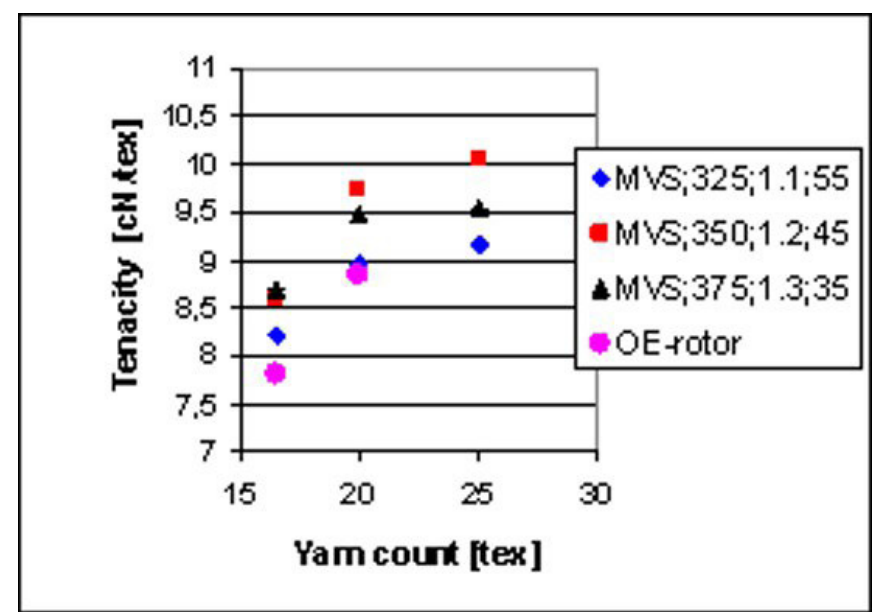

Figure 18. Yarn tenacity delivery speed $350 \mathrm{~m} / \mathrm{min}$ using the spindle diameter $1.2 \mathrm{~mm}$ show the highest values of tenacity, whereas the difference between tenacity values of yarn count of 16.5 tex spun at delivery speed $350 \mathrm{~m} / \mathrm{min}$ and $375 \mathrm{~m} / \mathrm{min}$ is not statistically significant. The Vortex yarns of fineness 16.5 and 25 tex show the lowest elongation values when the highest tested delivery speed was adjusted, whereas yarns of all fineness spun at delivery speed $350 \mathrm{~m} / \mathrm{min}$ have the highest elongation values. Wrapping fibres are twisted-in to the core fibre bundle by means of air swirl. The formation and influence of the swirl on the fibre bundle in the nozzle is affected by a combination of more factors (air pressure, nozzle angle, delivery speed, fineness of fibre bundle, spindle diameter). They can influence portion of fibres in the core and in wrapping layer, as well as a lead of helix of wrapping fibre ribbon, tightness of wrapping, compression of fibres in the yarn and thus yarn tenacity and elongation.

Vortex yarns showed statistically significant higher values of tenacity and elongation compared to the rotor yarns due to different arrangement of fibres in the yarn. Due to low straightening of fibres in the rotor yarn, the tenacity of individual fibres is not fully utilised in the yarn and thus rotor yarns have higher tenacity compared to Vortex yarns.

\section{Yarn abrasion resistance}

The average values and corresponding 95\% confidence intervals of number of revolution of abrasive cylindrical body till yarn breakage are shown in Figure 20.

As yarn becomes coarser, both Vortex and rotor yarns become more resistant to abrasion. This is caused by increasing number of fibres in the yarn cross-section with increasing yarn count. In terms of technological parameters of spinning, Vortex yarns spun with the smallest spindle diameter and the lowest delivery speed show the highest abrasion resistance and conversely. As explained above, the lead of helix of wrapping fibre ribbon in the yarn is small at low delivery speed compared to higher delivery speed, thus probably larger amount of wrapping fibres can be found per unit length of yarn. Therefore higher number of revolution of the abrasive body is necessary for damage of

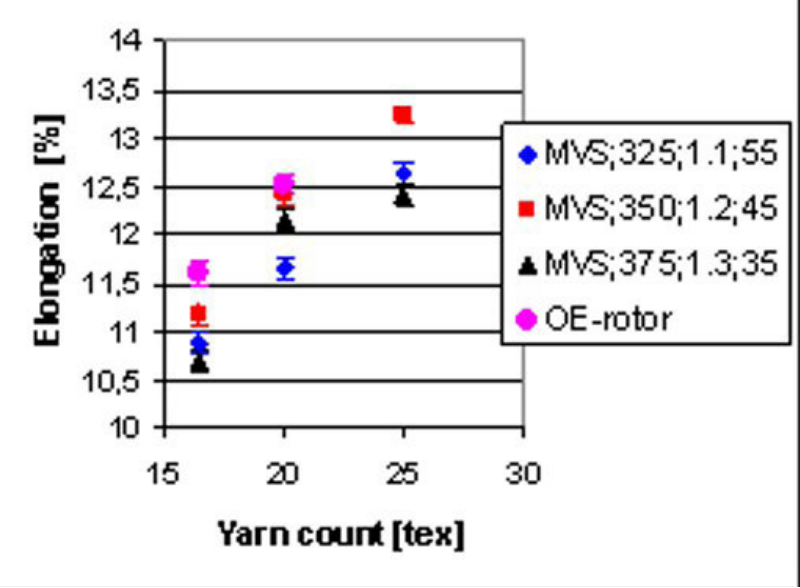

Figure 19. Yarn elongation 
wrapping fibre ribbon and consequently yarn breakage. The two-factor analysis confirmed statistically significant effect of yarn count and technological parameters of spinning on the yarn abrasion resistance at the significance level of $5 \%$.

The rotor yarns show the statistically significant higher abrasion resistance compared to Vortex yarns. It is caused by the fact that the all fibres in the bundle are true twisted in the rotor machine due to different spinning principle. The fibres are not so straightened and parallelised as core fibres in the Vortex yarn. Due to low parallelisation of fibres and thus increased number of friction points between fibres, the rotor yarn is probably able to resist the action of rotating body for a longer time while outer layer is damaged, compared to the Vortex yarn with straightened and non-twisted core fibres. The belt fibres of rotor yarn can contributes to higher abrasion resistance of rotor yarn.

\section{Yarn bending rigidity}

The average values and corresponding 95\% confidence intervals of yarn bending rigidity are shown in Figure 21.

The bending rigidity of both Vortex and rotor yarns increases with increasing yarn count, thanks to growing number of fibres in yarns and thus higher mass of fibres in the yarn cross-section. Comparing bending rigidity of Vortex yarns spun at different technological parameters, the yarns, spun at delivery speed of $325 \mathrm{~m} / \mathrm{min}$ have the highest values, except the count of 25 tex. The yarn bending rigidity decreases with increasing delivery speed and spindle diameter. But, due to higher variability of bending rigidity values, the two-factor ANOVA did not confirm the statistically significant effect of technological parameters of spinning on the bending rigidity. However, the significant effect of yarn count on the bending rigidity was confirmed.

Vortex yarns have significantly higher bending rigidity compared to rotor yarns. It is caused by different internal arrangement of fibres in the yarn, which is given by the technology of spinning. Fibres are arranged more parallel in the core part of Vortex yarn whereas all fibres are formed more randomly in the rotor yarn.

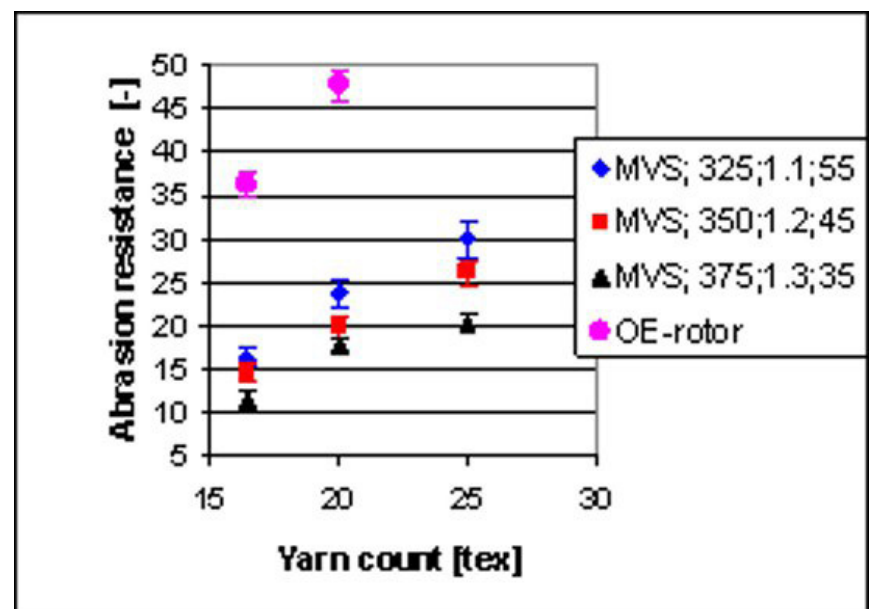

Figure 20. Yarn abrasion resistance (number of revolution of abrasive cylindrical body)

\section{Conclusions}

In this work, the relationship between technological parameters of spinning $100 \%$ viscose Vortex yarns of count 16.5, 20 and 25 tex and their selected geometrical parameters (the lead of helix of wrapping fibre ribbon, yarn diameter) as well as selected yarn properties (hairiness, mass irregularity, number of faults, yarn tenacity, elongation, abrasion resistance, bending rigidity) were investigated. The yarns were spun at three levels of delivery speed (i.e. speed of delivery roller of drafting unit, which influence speed of yarn passage in the spindle), spindle diameter and main draft. The air pressure was adjusted on a constant value during spinning of all type of Vortex yarns. Properties of Vortex yarn were compared with properties of rotor yarns of the fineness 16.5 and 20 tex made from the sliver of the same spinning lot.

It was confirmed that the Vortex yarn is formed by the core fibre bundle, which contains predominantly parallel fibre and the wrapping part consisting of fibre ribbon twisted around the core. The ribbon wraps the core fibre bundle in the helix trajectory. The number of twist of wrapping fibre ribbon was determined by measuring the lead of helix of the ribbon. Experimental measurement and two-factor ANOVA of obtained values showed statistically significant effect of technological parameters of spinning (i.e. spindle diameter, delivery speed) on some properties of tested CV vortex yarns. Results showed that using the smallest tested spindle diameter and the lowest delivery speed probably led to intensive action of swirl air on the fibres and thus the yarns have higher number of twist of wrapping fibre ribbon. Using the smaller spindle diameter, fibres are more compressed in the yarn which shows smaller yarn diameter; probably in combination with lower delivery speed, wrapping fibres are more twisted-in to the core and thus yarns have lower hairiness values and higher abrasion resistance. However, yarns, spun using the smallest tested spindle diameter and the lowest delivery speed, have higher mass irregularity and the number of faults due to used higher main draft compared to other adjustments. Technological parameters of spinning do not affect yarn bending rigidity. Although the results showed the significant influence of spinning parameters on yarn tenacity and elongation, their

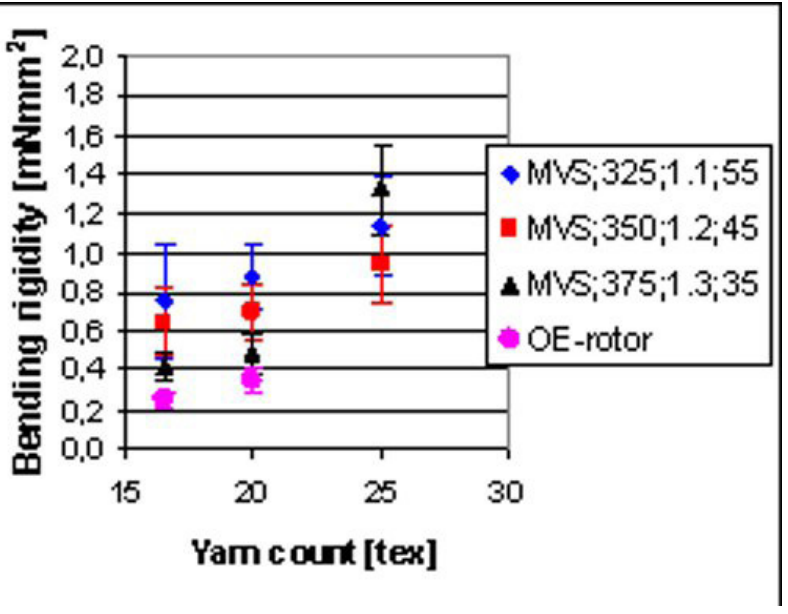

Figure 21. Yarn bending rigidity 
systematic effect was not evident, even though Ortlek et al. [9] found that increasing spindle diameter decreases the tenacity values of viscose yarns of count 20 tex spun at delivery speed $350 \mathrm{~m} / \mathrm{min}$. The influence of technological parameters on the Vortex yarn tenacity and elongation is more difficult. The action of swirling air, by means of it the trailing ends of wrapping fibres separate from the core bundle and consequently twist-in to the core, is influenced not only by combination of observed technological parameters (main draft, delivery speed, spindle diameter) but also yarn count. Also we can consider the mutual effect of air pressure and monitored parameters on the action of swirling air on the fibre bundle.

The rotor yarns spun from the same raw material as Vortex yarns showed higher yarn diameter and hairiness, lower tenacity, higher elongation, better yarn irregularity and lower thick $(+50 \%)$ and thin places $(-50 \%)$, better abrasion resistance and lower bending rigidity compared to Vortex yarns.

\section{Acknowledgement}

This work was supported by the project Clutex No. 5.1.SPK02/024.

\section{References}

[1] Klein, W. (1997). The Technology of Short Staple Spinning, Manual of Textile Technology, 2nd ed., The Textile Institute, England.

[2] Murata Machinery Ltd. (2005). Vortex Yarn guide book, Retrieved 08 24, 2005, Web site: http://www.muratecvortex.com

[3] Basal G. (2003). The structure and properties of Vortex and Compact spun yarns. Dissertation. Faculty of North Carolina State University, Raleigh. Retrieved 2013, 5, 12, Web site: http://repository.lib.ncsu.edu/ir/handle/1840.16/4631

[4] Basal, G., Oxenham, W. (2003). Vortex Yarn vs. Air-Jet Yarn. AUTEX Research Journal, 3(3), 96-101.

[5] Soe, A. K., Takahashi, M., Nakajima, M. et al. (2004). Structure and properties of MVS yarns in comparison with ring yarns and open-end rotor spun yarns. Textile Research Journal, 74(9), 819 - 826.

[6] Basal, G., Oxenham, W. (2006). Effects of some process parameters on the structure and properties of Vortex spun yarn. Textile Research Journal, 76 (6), 492-499.

[7] Kuthalam, S. E., Senthilkumar, P. (2013). Effect of Fibre Fineness and Spinning Speed on Polyester Vortex Spun Yarn Properties. FIBRES \& TEXTILES in Eastern Europe, 21, 5(101), 35-39.

[8] Price, C., Senter, H., Foulk, J., et al. (2009). Relationship of Fiber Properties to Vortex Yarn Quality via Partial Least Squares. Journal of Engineered Fibers and Fabrics, 4 (4).

[9] Ortlek, H. G., Nair, F., Kilik, R., Guven, K. (2008). Effect of Spindle Diameter and Spindle Working Period on the Properties of $100 \%$ Viscose MVS Yarns. FIBRES \& TEXTILES in Eastern Europe, 16, 3 (68), 17-20.

[10] Erdumlu, N., Ozipek, B., Oztuna, A., Cetinkaya, S. (2009). Investigation of Vortex Spun Yarn Properties in Comparison with Conventional Ring and Open-end Rotor Spun Yarns. Textile Research Journal 79 (7), 585-595.

[11] Erdumlu, N., Ozipek, B., Oxenham, W. (2012). The structure and properties of carded cotton vortex yarns, Textile Research Journal, 82 (7), 708-718.

[12] Murata Machinery, Ltd. (2007). Vortex 861 Spinning Machine, Retrieved 06 05, 2008, Web site: http://www. muratec-vortex.com

[13] Yonenaga, A. (2003). Verbessertes Luftspinnverfahren, ITB International Textile Bulletin, 46 (4), 40-42.

[14] Křemenáková, D., Vyšanská, M. Militký, J., Moučková, E., et al. (2008). Properties of Vortex yarns, Research study, Technical University of Liberec and Clutex (Liberec).

[15] Kolčavová Sirková, B., Mertová, I. (2013). Prediction of woven fabric properties using software ProTkaTex. AUTEX Research Journal, 13 (1), 11-16.

[16] ČSN EN ISO 2062. Textiles - Yarn from packages Determination of single-end breaking force and elongation at break.

[17] Střiž, B. (2002). Mechanics of textiles. Faculty of Textile engineering, Technical University of Liberec (Liberec).

[18] Kolčavová Sirková, B., Mertová, I (2004). Internal standard: Bending rigidity of yarn. Research Centre of Textiles, Faculty of Textile Engineering, Technical University of Liberec (Liberec)

[19] Tyagi, G.K, Sharma, D., Salhotra, K.R. (2004). Processstructure-property relationship of polyester-cotton MVS yarns: Part I - Influence of processing variables on the yarn structural parameters. Indian Journal of Fibre Textile Research, 2004 (29), pp. 419-428.

[20] Neckář, B. (1990). Yarn - structure and properties, Prague, Czech Republic. 